to several times their original length. In the same sandstone quartz pebbles have been pulled out and flattened, while sericite has been largely developed along the cleavage planes. The pressure can be shown to have been directed mainly from the south-east. (2) The second locality is in the midst of the Laurentian area of Buck's County, and is known as Van Artsdalen's Quarry. A mass of crystalline limestone is here mingled with an eruptive diorite in such manner as to show that it had actually flowed like an igneous rock, and had caught up inclusions. The results of extreme metamorphism are exhibited in the development in the limestone of graphite, wollastonite, and other minerals. The chemical changes and interchange of elements which might result from a loosening of molecular combinations under extreme pressure and their subsequent "regulation" into new compounds were discussed as among the phenomena of mechanical metamorphism. (3) As an American instance of the conversion of an intrusive diabase dyke into amphibolite schist, analogous to the case recently described by Teall, a long narrow belt of sphene-bearing amphibolite schist in the City of Philadelphia was adduced. This belt with distinctive mineralogical characters cuts across the metamorphic mica schists of the region unconformably, and is believed by the author to be a highly metamorphosed intrusive dyke of Lower Silurian age. The original augite or diallage has been completely converted into fibrous hornblende, and the influence of pressure is shown in the perfectly laminated character of the schist in the close foldings produced, and in the minute structure of the rock. Some interesting details of the latter having been photographed, diagrams constructed from these were exhibited. These showed that the rock was traversed by a parallel series of slips and crushings, and that about such lines of faulting and crushing there was a peculiar arrangement of the lines of hornblende crystals, not very unlike the arrangement of iron filings about the poles of a magnet, such as could not be satisfactorily explained by any theory of aqueous deposition, but pointed to a lamination by pressure.

\section{SECTION D-BIOLOGY}

On the Cause of the extreme Dissimilarity between the Faunas of the Red Sea and Mediterranean notwithstanding their recent connection, by Prof. Edward Hull, LL.D., F.R.S.-The faunas of the Mediterranean and of the Red Sea are so unlike that if the beds of the two seas were upraised, and their contents examined, naturalists would probably refer them to distinct geological periods. The dissimilarity is greater than was formerly supposed. In Woodward's "Manual of the Mollusca" it is stated that seventy-four species of mollusks are common to the two seas, but Prof. Issel, of Genoa, places the number at eighteen, or about 2 per cent. Equal differences exist if we compare other great groups of life; in fact, as Prof. Haeckel well observes, the fauna of the Red Sea is related to that of the Indian Ocean, the fauna of the Mediterranean to that of the Atlantic. This extreme dissimilarity would not surprise us if it were not for the proofs of recent connection between the two seas. Evidence of old sea margins, up to about 220 feet above the present sea-level, are frequently found along the Nile and in the valleys and plains of Philistria. As many of the marine forms found in these deposits still exist, the date of the submergence may be safely referred to that of the Pliocene; but it continued to a later period, and (in the author's opinion) it to some extent remained to the time of the Pharaohs. The existing fauna probably date; back to Eocene times, when the ocean spread widely over the area in question. In the Miocene period the main outlines of land and sea as we now find them were marked out, the deposits of this age being here small and local. Under the extremely different conditions existing in the two areas, the fauna during and after the Miocene period became differentiated. The connection re established during and after the Pliocene period was insufficient to destroy these differences, although it allowed a mingling of forms to some extent. The maximum submergence was about 220 feet; but as the summit level between the two seas is about 50 feet, the depth of water would only be about I 70 feet at the maximum. Only littoral and shallow-water forms would cross in the adult state ; but many forms inhabiting deeper water in the adult state might have crossed when in the free-swimming larval state. When the land again rose, and the marine straits were finally effaced, the different physical conditions of the two seas would again come into effect. The difference of temperature is now very considerable, and probably was much greater during the Glacial period, especially if, as appears probable, the eastern or Levant basin of the Mediterranean wer separated from the others; for into this would flow the cold waters of the Black Sea and of Central Europe, whilst the Red Sea would receive warm water, and be itself exposed to the rays of a tropical sun. It would be an interesting subject of inquiry-Which of these faunas most closely resembles that of the original stock?

On the Tay Whale (Megaptera longimanx) and other Whales recently obtained in the District, by Prof. Struthers.-Prof. Struthers gave a description of the various parts of the anatomy of the whale. In addition to the Tay whale members of three other whales recently obtained in the district were exhibited for the purpose of comparison, and the analogy of its structure to that of other animals was specially referred to in order to show its identity with the mammal. Prof. Flower joined in the discussion which followed, and remarked that they now had an idea at least as to the origin of the whale : it carried its pedigree in every part of its body. It had been thought that the mammals that live upon land had been derived from progenitors that formerly lived in the sea, and that the mammals may have passed through an aquatic or marine stage before they took to land, but the observations of anatomy showed that this cannot have been the case. There was no doubt that the whale had been derived from a four-footed land mammal. All observations, for example, had shown that at some period of their life whales have a hairy covering, generally in the region of the mouth, that hairy covering being functionless and very often lost even before birth. In the same way whales at an early stage of their existence are furnished with a complete set of teeth, the rudiments of the teeth of the land mammal. The organ of smell, although in a rudimentary state and in some species almost entirely gone, also points to the origin of the whale.

Some Points in the Anatomy of Sowerby's Whale, by Prof. Turner.-Prof. Turner remarked that Mesoplodon bidens, or Sowerby's whale, of which he had dissected two specimens, was now for the first time dissected so that the viscera of this whale were seen by any anatomist, or that its tail and paddle, or fin, had been figured. 'The tail presents a very material difference from the customary tail in the cetacea in having the posterior border smooth instead of notched. Dr. Turner called attention in detail to the intestinal and limb structure of this species of whale, showing the affinity or resemblance of the cetacea to the reptilious and the amphibious, particularly in reference to the corpus. Prof. Flower said he was glad to find that Prof. Turner had found-some intention for the muscles of the corpus. For all that they were very rudimentary as compared with the same muscles in other animals, and he thought that he might have to modify his views on this point as he had had to do in regard to many other things throughout life. Prof. Marsh, of Yale College, said the intermediary bone pointed out by Prof. Turner interested him much.

On the Cervical Vertebre of the Greenland Right Whale, by Prof. Struthers. - The reduced condition of the upper and lower transverse processes was commented on, and the meaning of their different parts explained; also the completely fused condition of the bodies of the seven vertebræ. A nearly similar condition of the neck of the Pilot Whale (Globicephalus melas) was demonstrated, showing in the young condition the two body epiphyses on the rudimentary vertebræ. Other specimens illustrated the fibrous condition of the transverse processes in the Narwhal and Beluga.

On the Development of the Vertebre of the Elephant, by Prof. Struthers. - The point was that in the anterior vertebræe the neural arches meet behind the body, covering it deeply, and shutting it entirely out from forming any part of the wall of the spinal canal.

On the Development of the Foot of the Horse, by Prof. Struthers. -Dr. Struthers called attention to the fact that the epiphysis of the rudimentary metacarpal and metatarsal bones is not at the upper or functional end, but at the reduced end or "button," from which only a slender ligament proceeded. This he considered a most interesting fact, one wbich completed the chain of evidence of the descent of the horse. There was a reason why the epiphyses should be there in the hipparion and previous forms from which the horse of the present day was descended. The development of the corresponding bones in man, the cetacea and various other mammals, was given in illustration. 
A specimen was shown of a two-toed horse. The valuable researches of Prof. Marsh on the descent of the horse were specially alluded to. Dr. Struthers demonstrated another fact connected with the development of the foot of the horse-that the first phalanx, or pastern bone, has an epiphysis at both ends.

On the Viscera of Gymnotus electricus, by Prof. Cleland. Independent of its electric organs, this fish has a number of remarkable internal peculiarities. The curious spongy protuberances of the mucous membrane of the buccal cavity are well known to zoologists. The two swimming-bladders are remarkable for their relation to the kidneys; the anterior swimmingbladder being a small structure between their anterior extremities, and the larger posterior swimming-bladder being situated altogether behind their under hinder ends, while the duct of the latter ascends by the left side of the renal outlet, to be joined by the duct of the other bladder before entering the gullet. The pylorus also is remarkably contracted. But the most striking and altogether curious arrangements are seen on the ventral wall of the abdomen. The intestine passes forward the whole length of the abdominal cavity to the vent, and on its under side is a long renal duct as wide as itself, and opening immediately behind the vent ; while, opening into this duct close to its outlet, are the ducts of the two ovaries, which lie one on each side, their morphologically anterior extremities placed posteriorly, as if in process of development these organs had been pulled around from their proper sub-vertebral position until completely inverted.

The Stiracle of Fishes in its relation to the Head, as developid in the Higher Vertebrates, by Prof. Cleland.-A very extraordinary mistake can be shown to be prevalent among embryologists, to the effect that the spiracle corresponds with the tympanum and external anditory meatus in the higher verte brates. This is not the case. The spiracle is pre-oral; the tympanum is post-oral. The apparent sequence of the spiracle with the branchial clefts occurs, as Balfour described it, in the embryo of the dog-fish; but for all that, and although it has rudimentary external gills attached to its margins in the enbryo, it is in front of the mandibular arch and above the maxillary lobe. Between the middle and lateral frontal processes is the nostril ; bctween the lateral frontal process and the mandible is the space into the upper part of which the eyeball projects, and from which the lachrymal duct is developed; while between the first and second visceral lobes is the external ear; and it is highly probable that the upper part of the first branchial cleft is homologous with the clefts in front of and behind the lateral frontal process. Thus a certain amount of homology would exist between the spiracle of fishes and the lachrymal duct.

Is the Commissural Theory of the Corpus Callosum Correct? by D. J. Hamilton, M.B., Professor of Pathological Anatomy, Aberdeen University. - The results recorded by the author were obtained by certain special methods of preparation. They went to prove that the corpus callosum is not an inter-hemispherical commissure, as is generally supposed, but that it is in reality the decussation of a particular system of fibres on their way downwards to join the inner and outer capsules. These fibres are not to be confounded with the motor and other direct fibres derived from the cerebral cortex, and which decussate at some point lower down.

The Evilence of Comparative Anaromy with regard to Locaiisation of Function in the Cortex of the Brain, by Alex. Hill, M.A., M.B. Cambridge.-The object of the paper was to show that the theory of the localisation of function in the cortex of the brain must be submitted eventually to comparative anatomy for proof. The key to the arrangement of the lower parts of the central nervous system is to be found, as the author had elsewhere shown, in its segmental disposition: the grey matter is disposed in clumps the cells of which bear a definite numerical relation to the fibres of body nerves. The problem discussed in the present paper was the relation of the grey matter of the cortex to this lower grey matter, and therefore to the body nerves. Is each region of the cortex equally in relation with all the segments of the "central grey tube"? or is the cortex also divided up into areas, the superficies of each of which varies as the amount of grey matter in the clump of the lower system with which it is related, and therefore as the number of fibres in its associated nerve. For this investigation guides to the delimitation of the cortex are necessary, and no others are available for the purpose if the fissures fail. The homological value of the fissures is, however, established by the study of adult and foetal brains. They are remarkably constant in their arrangement throughout animals of the same type, and in animals of different type they are very constant with regard to the order of their appearance, their progressive extension and permanent depth. The author of the paper expressed himself content, on account of the precision with which the fissures respond to the ordinary tests of homology, to place himself unconditionally in their hands, and the boundaries of the various regions of the cortex heing thus marked out, it remains to devise a system of mensuration by which the superficial area of each region of the cortex may be determined for comparison with the cross-sections of the several nerves. As yet no satisfactory method of measurement has been devised, but even in the absence of exact data important results can be obtained by the observation of the brains of such animals as are conspicuous for excess or deficiency in the development of the muscular system or of one or more of the senses. As examples of such results Mr. Hill exhibited diagrams of the brai ıs of the sheep, cat, pig, $\mathrm{dog}$, and otter, enlarged from tracings of the pictures in Leuret and Gratiolet's Atlas. It was shown that, although it is impossible, as yet, to map out the brain into areas associated with the several nerves, it is quite possible to predict from the appearance of the brain the principal sensory and motor endowments of the animal to which it belonged. In the main Mr. Hill's results confirm those already obtained by Ferrier and other experimental physiologists; they seem, however, to show that they are open to correction in certain important points with regard to the areas allocated to the senses of smell, hearing, and facial sensation.

The Action of Cold on Microphytes.-Prof. M'Kendrick, Glasgow, gave an interesting account of the methods of trying to destroy small organisms like bacteria, not as is commonly done by heat, but by cold. It is known that by means of Coleman's cooling machine meat may be kept from putrefying for a considerable time, but in attempting to sterilise a putrescible solution by means of cold, it was found that, though in some cases putrescence was delayed, in no case were the organisms completely destroyed. Organic fluids were exposed to temperatures more than $120^{\circ}$ below $0^{\circ} \mathrm{F}$., but on thawing they were found to contain living organisms still. Thus the hope of preserving putrescible matter by means of cold-an important economical result--is, so far as investigation yet goes, destroyed. The organisms under cold seem to be in a nearly solid state, though we cannot call it a crystalline state. In a paste solution the water is crystallised under cold, the paste remaining spongy. Possibly cold may separate from these minute organisms the water they contain, and this water is again absorbed on thawing. Meat under cold becomes very friable, while yet minute fragments of it show the same microscopic constitution of muscle. It is well known that frogs have been found in blocks of ice and been revived. Frogs have been frozen at $20^{\circ} \mathrm{F}$. in about half an hour. On thawing slowly the animal, in two instances, completely recovered. When it was frozen for longer than half an hour it did not recover; but, though reflex action was gone, there remained some irritability both in nerves and muscles. It was found also that certain vital functions may be arrested by cold, and thus conceivably higher organisms may be kept vitally inert for an indefinite time. Experiments were also tried on warm-blooded animals. A rabbit subjected to a temperature $100^{\circ}$ below $0^{\circ} \mathrm{F}$. recovered. No temperature lower than $73^{\circ}$ below $0^{\circ} \mathrm{F}$. has been obtained in free atmosphere. Prof. M'Kendrick gave a short sketch of the literature of the subject.

The Action of Oronised Air upon Micro-Organisms and Albumen in Solution, by J. J Coleman, F.I.C., F.C.S.-This paper described a number of experiments conducted by the author in conjunction with Prof. McKendrick, F.R.S., being supplementary to their joint investigation upon the influence of cold on microphytes. Air artificially impregnated with ozone by means of a Ruhmkorff coil, so as to contain a much larger percentage of ozone than any natural atmospheric air, was passed continuously through a I per cent. solution of white of egg placed in a glass flask, the inlet and outlet tubes of which were carefully plugged with cotton wool previously to commencing the experiment. It was found that a stream of air containing an amount of ozone equal in weight to the albumen in solution passed through roo c.c. of the liquid for thirty hours, failed in producing the slightest trace of oxidation, and that the ozonised air passed through the liquid quite unaltered. During the course of the experiment and for six days following the development of micro-organisms ceased, but at the end of that time, and notwithstanding the cotton wool plugs, the liquid became slightly 
turbid from the presence of organisms. As dilute hydrogen peroxide is without action upon albumen, the conclusion seems inevitable that albumen is practically indestructible by any atmospheric agency without previous splitting up by micro-organisms, and further, that whilst micro-organisms cannot develop, and are probably killed in an ozonised atmosphere, these spores are not easily destroyed by its agency. These results confirm the surmise of the late Dr. Angus Smith that putrefaction is a necessary preliminary to oxidation in all cases of natural river purification. Prof. Burdon Sanderson, Dr. W. B. Carpenter and Capt. Douglass Galton all commented upon the practical value and interest of this paper, Capt. Douglas Galton observing that the sooner organic matter of sewage is got on to land the better.

The Use of Graphic Representations of Life-Histories in the Teaching of Botany, by Prof. Bower. - This was a paper referring to a series of diagrams prepared by the author to bring in review the chief facts in the life-history of the moss, fern, equisetum, Selaginella, a conifer, and an angiosperm. Prof, Bower pointed out that these diagrams could be extended to include lower forms, and that they are only intended for use after the student has mastered the facts in detail in the laboratory. Having described the diagrams and referred to some interesting processes of vegetative reproduction in the mosses and ferns, the author then proposed for discussion a series of questions as to the advisability of employing such diagrams, or of extending their use. The discussion which followed was taken part in by Sir J. Lubbock, Profs. Bailey Balfour (Oxford), M'Nab (Dublin), Trail (Aberdeen), Mr. Marshall Ward (Owens College), and others, and several suggestions were proposed for rendering Prof. Bower's graphic representations still more graphic.

A New Theory of the Sense of Taste, by Prof. J. Berry Haycraft. - The author showed that "quality" in this sense depends upon the nature of the atoms found in the sapid molecule. A study of the periodic law demonstrates that similar tastes are produced by combinations which contain elements such as lithium, sodium, potassium, which show a periodic recurrence of ordinary physical properties. Among the carbon compounds those which produce similar tastes are found to contain a common "group" of elements. Thus organic acids contain the group $\mathrm{CO}$. OH, the sweet substances $\mathrm{CH}_{2} \mathrm{OH}$. There is no relation between quality of sensation and gross molecular weight, except that substances of either very small or very great molecular weight are not tasted at all.

On the Hybridisation of Salmonida at Honvie'sun, by Francis Day.-During the last cleven years Sir J. R. Gibson-Maitland, at Howietoun, near Stirling, has devoted much attention to this subject, and gone to great expense in order to efficiently carry out the many experiments he has instituted, while he has likewise afforded the author facilities for personally watching many of them, and furnished him with data as well as with specimens. When we consider that the ova of teleostean or bony fishes have, as a rule, to be fertilised by the milk of the males diffused in the surrounding water, it is not difficult to believe that this fluid from the male of one genus might come into contact with the eggs from fish of another species, genus, or even family, and a hybrid offspring be thus occasioned. But the size of the micropyle of the ovum and that of the spermatozooid of the milt must be of conforming capacities, or fertilisation would be a physical impossibility. It would appear from the experiments made that the following conclusions may, with more or less probability, be drawn :- (I) Salmon and trout, trout and char, and different species of char, may interbreed and give rise to fertile hybrids. (2) Hybrids raised from Lochleven trout eggs fertilised by salmon milt, breed in their fourth year, similar to young female salmon hept under the same conditions. (3) The anodromous instinct is not lost in these trout and salmon hybrids. (4) Judging from the period of breeding in the foregoing hybrids, the male element is prepotent. (5) In hybrids raised from Lochleven trout eggs fertilised by the milt of the American char, the male element would appear to be prepotent, if we judge simply by the colour of the offspring. (6) In hybrids raised from American char eggs fertilised by the milt of the Lochleven trout, the female element would appear to be prepotent, if wo judge simply by the colour of the offspring. (7) In hybrids raised from American char eggs fertilised by the milt of the British char, the male element would appear to be prepotent, if we may judge simply by the colour of the offspring. (8) In all instances of hybridisation between different species, as between salnion and trout, or trout and char, numerous instances of mal- formation and great mortality occur among the offspring, but much less when two forms of char are intercrossed. (9) In intercrossing hybrids both the eggs and milt were found to be fertile, but the malformations and mortality very great. The parents, however, at Howietoun are not yet of sufficient age to admit any safe deductions on this head. (10) The age of the parent exercises great influence on the vitality of the offspring, for, when very young, we may expect a large percentage of malformations, as well as dropsy and other diseases of the offspring.

Chinese Insect White Wax, by A. Hosie. - The author began with a reference to the European and Chinese writers who mention Chinese insect white wax, and then proceeded to say that, although the province of Ssu-chuan, in Western China, where he has been stationed for the last three years, is the chief wax-insect and wax-producing country in the Empire, insects and wax are found in other provinces. Mr. Hosie was called upon by the Foreign Office to collect for Sir Joseph Hooker specimens connected with, and all possible information on, the subject of this industry, and he states that the present paper is a revision, with additions, of a Report already published in a Parliamentary paper in February last. He describes the insectproducing country, the tree on which the insects are propagated, the insects themselves, and their transit from the valley of Chienchang, their breeding-ground, in the west of Ssu-chuan, across the mountains to Chia-ting $\mathrm{Fu}$, the habitat of the wax tree. This t1e? is then described, and details are given of the treat. ment of the insects, their suspension on the trees, the depositing of the wax, and of a parasite on the insects. The method of removing the wax from the branches of the tree and of preparing it for market is then explained. The author then detailed the result of an examination of the insects after the wax has been fully deposited, finally passing to the annual quantity of insect white wax produced, its value, and uses.

On the Size of the Brain in Extinct Animals, by Prof. O. C. Marsh.-Prof. Marsh, of Yale College, said that for fifteen years he had directed his attention to the subject of the size of the train in extinct animals. In every instance he found that the mammals from the lower Tertiary had very small brains. He carried out his investigation into the upper Tertiary, and found that the brain was much larger in the pliocene than in the miocene. All the tertiary mammals had small brains; there was a gradual increase in the size of the brain during this period; and this increase in the size was generally in the cerebral hemisphere or higher portions of the brain. In some groups the convolution of the brain had gradually become more complex. In some the cerebellum and the olfactory lobes had even diminished in size. There was now evidence that the same general law of brain growth holds good for birds and reptiles from the Jurassic period to the present time. The brain of an animal belonging to a vigorous race fitted for a long survival was larger than the average brain of that period in the same group, and the brain of a mammal of a declining race was smaller than the average brain of its contemporaries of the same group. The small animals now existing had proportionally larger brains than the larger animals, and young animals had proportionally larger brains than adult animals. They found some interesting examples which threw light on this question. For instance in the Eocene they had an animal, the oldest known ancestor of the rhinoceros, and it had an exceptionally large brain. Taking all the facts together it seemed as though this brain growth was an important element in the survival of animals. If the animal became large and unwieldly with a small brain, it would be liable to suffer from any change of climate. In other words, in early times the big brain conquered as it is the big brain that conquers in civilisation to-day. Prof. Flower said it was satisfactory to find a case where the facts worked out coincided with previously-formed theories, because that was not always the case, and sometimes the facts or the theories had to go to the wall. In this case they had no such difficulty; and they had to thank the American Government for the way in which it had taken up Prof. Marsh's work and were disseminating it.

On the Systematic Position of the Chameleon ant its Affinities with the Dinosauria, by D'Arcy W. Thompson, B.A. -The author believes that the great anatomical differences which separate the Chameleon from all other Lacertilia are connected with marked resemblances to the Dinosauria, especially the group Sauropoda. The shoulder-girdle is quite identical with that of $(e . g$.$) Brontosaurus, but differs wholly from that of the$ Lacertilia in the simple form of the scapula and coracoid, the absence of coraco-scapula fenestrations, of clavicle and inter- 
clavicle. Equally marked affinities with the Dinosauria may be traced in the carpus and tarsus, sternum, pelvis, and skull. While similarly the comparatively large size of the cerebellum, the absence of a urinary bladder, and the presence of pulmonary diverticula or rudimentary air-sacs, are all foreshadowings of ornithic structure.

The Origin of the Fishes of the Sea of Galilee, by Prof. Hull.Of the abundant fishes of the Sea of Tiberias nearly one-half of the species are peculiar to the lake and its tributaries, while of the rest only one, Blennius lupulus, belongs to the ordinary Mediterranean fauna; two others are found in the Nile; seven other species occur in the rivers of South-Western Asia; and ten more are found in other parts of Syria. Tristram considered that this assemblage pointed to a close affinity of the fauna of the Jordanic basin with that of the rivers of tropical Africa; but what most struck the observer was perhaps the speciality of the species to Jordanic waters, sixteen out of a total of thirty-six species being peculiar. Assuming that the forms which are common to jordanic and other waters had been distributed in a manner similar to that by which they had to account for the distribution of lacustrine forms in other parts of the world, they had yet to account for the presence of the forms which were special and peculiar. After referring to the formation of the Jordanic basin, Prof. Hull argued that by the subsidence of the floor of the sea along the line of the Jordan valley an inland lake was formed whose waters were first derived from those of the ocean itself, in which were enclosed the fishes, mollusks, and other forms which inhabited these waters themselves. The law of "descent with modification" would come into operation, and they might suppose that throughout the Miocene and Fliocene periods the process of modification in form, colour, and habit gradually proceeded. The fittest forms would survive, and differentiation between those of the outer and inner seas would result in an almost entire specific change. Prof. Hull also read a paper on the cause of the extreme dissimilarity between the faunas of the Red Sea and Mediterranean, notwithstanding their recent connection.

The St. Andrews Marine Laúratory.-Prof. M'Intosh stated briefly the structure and arrangement of the marine laboratory at St. Andrews, and made some general remarks on the work done during the last nine months there. A great many of our food fishes, he said, were carefully examined in regard to the development of the eggs and the growth of the young fishes. About twenty species were examined in this way. They cxperienced some difficulty with some of the forms, on account of their voracity, particularly with the cod. They found that a corl of five inches long would swallow a cod of three inches, and if it could not get it all down at once, it would keep it in its throat till the head part was digested, and then draw in the tail. Mollusca were studied chiefly in connection with the development of the mussel, but he might say that very hazy notions were held in regard to it. Some larger forms were also examined, including porpoises and sharks. One porpoise was extremely interesting. He had noticed it for some time in the bay, and that its motions were very peculiar. He could not make out what it was doing there so constantly in shallow water. But some days afterwards a large female was caught in the salmon nets, and they found that it was a female giving milk. Its milk was of a most interesting kind, and formed the subject of examination and analysis by Prof. Purdy. It was as dense as cream, and of a deep yellow colour.

On a Chemical Difference between Living and Dead Protoplasm, by Dr. Oscar Loew, of Munich.-Protoplasm, it was found, contains certain aldehyd groups, which account for the extreme mobility and readiness of change in living protoplasm. These aldehyd groups can be reduced by very dilute alkaline solutions of silver salts. Spirogyra, one of the lower alge, acts on this solution in a peculiar way. Living protoplasm reduces the salt, while dead protoplasm does not. The specific gravity of the protoplasm of Spirogyra was increased, and was found to c ntain silver deposited in its interior. Argyria, or the effect of nitrate of silver on the human subject in certain disenses, was found in these algre. Thus was shown a specific chemical difference between living and dead protoplasm. Ordinary poisons, such as prussic acid and strychnine, have no such striking effect on lower organisms, but a poison to all protoplasm is hydroxylamyl. Prof. Burdon-Sanderson said that this investigation had more importance than might at first appear, for it had arisen out of the epoch-making paper of Pfliger. Pflüger concluded that there must be a chemical change in the transition from living to dead protoplasm, and Dr. Loew took up the question as to what exactly this change was. His investigations are an important step in deciding this most important question. Prof. Stirling said this gave us a new test for living protoplasm. The chief thing to settle was what exactly causes reduction of the silver.

Disestion of Proteids in Plants, by Sidney Martin, M.D. (Lond.), B.Sc., M.R.C.P.-Of proteolytic ferments occurring in plants two kinds have been described--one acting like animal pepsin, and occurring in carnivorous plants, in the seeds of vetches, hemp, flax, barley, and malt, and the fruit of the fig, Ficus cerica; the other acting like animal trypsin (pancreatin) and occurring in the juice of the green fruit of Carica papaya (the papaw tree). The use of these ferments in the plant economy has only been surmised by testing their action on animal proteid, from which they form peptones. It is a question whether they form peptones from the proteid occurring in the individual, and from two considerations. It is doubtful whether a true peptone exists in plants-by which I mean a proteid soluble in water, and not precipitated by boiling, nitric acid, or acetic acid and potassic ferrocyanide. Vines (Fournal of Physiolooy, vol. iii.) concludes that the body called vegetable peptone is hemialbumose (Meissner's a.peptone). It is also evident that the action of these ferments on the proteids will be slow in comparison to the action of animal proteolytic ferments ; thus there might appear the proteids intermediate between albumen and peptone, which Kuihne and (hittenden call albumoses (Zeitschrift f. Biologie, Bd. xx.). These questions I attempted to settle in the case of the papaw juice. I first of all extracted the proteids, which consisted of a globulin, corresponding to animal paraglobulin; two albumoses, which I propose to call $\alpha$ - and $\beta$-phytalbumose. The $\beta$ form is precipitated; the $\alpha$ form is not thrown down by boiling; a vegetable albumen corresponding to egs-albumen. The effect of pure papain (the proteolytic ferment of the papaw juice) was tested on each of these bodies, but from none of them was a true peptone formed ; only a body corresponding to Meissner's b-peptone. The very slow proteolysis explains the limitation of the formation of the final products of proteid change. Leucin and tyroin were formed. Full details of methods and results will be found in the forthcoming Fournal of Physiology, September I4, I885.

On the Application of the Anatomical Method to the Determination of the Materials of the Linnean and old Herbaria, by Prof. L. Radlkofer.-Prof. Radlkofer spoke generally of the anatomical method of botanical study, and dwelt on the results that had already been accomplished by it. IVith the aid of the anatomical system he advocated an extensive review of the herbaria of the country with reference to the writings of their former possessors. These herbaria should henceforth not merely be preserved; there should be the diffusion of new light on their contents so as to become useful to every one in a scientific sense, even to those who are unable to look through them. At some length he demonstrated the value of anatomical characters in systematic botany, and concluded with an appeal to all English botanists to direct their attention and their influence to the accomplishment of the work. In the accomplishment of this the British Association might, perhaps, givc substantial assistance.

No'es on Experiments as to the Formation of Starch in Plants under the Influence of the Electric Light, by Mr. M. Ward, of the Owens College, Manchester.-The experiments, Mr. Ward said, were made not so much to determine a point already determined generally - that plants can be grown under the influence of the electric light-as to discover how far the electric light can be used for teaching pirposes and investigations in the laboratory so to spenk as an artificial sunlight. It would obviously be of enormous advantage to the vegetable physiologist if experiments could be easily performed under the infuence of electric light. He explained the experiments he had made in the laboratories at the Owens College, Manchester, and at the residence of $\mathrm{Mr}$. W. Crossley, of Bowden (who kindly placed a powerful arc lamp at his disposai), on this interesting subject, and described the means that had been employed in devising and conducting the experiments. Under a powerful arc light the results had been fruitful; but small clusters of Swan lamps had yielded no satisfactory results, at any rate at low temperatures. The subject requires still further examination, however, and Mr. Marshall Ward intimated that he intended to carry on the experiments, so that at a future date he might be able to convey more detailed information than could be given in a paper of a preliminary character. The plants employed were hyacinth potato, Algæ, 
Faba, Phaseolus, Dicentra, and the vine, and some interesting remarks on methods, \&c., were made in the discussion which followed.

On the Coloration of the Anterior Segments of the Maldanide, by Allen Harker, F.L.S., Professor of Natural History, Royal Agricultural College, Cirencester.--The author, while studying the circulation and respiration of annelids at the zoological station at Naples, had been specially interested in the Maldanidæ, from their partially tubiculous habit and the brilliant coloration of their anterior segments. The bands of colour usually ornament the anterior segments, beginning with the second or third, and continuing to the ninth; but the distribution of the coloured hands differs widely in the different species. The colour in living or freshly-killed specimens is of a rich rose madder colour, shading off in each segment to a brighter rose-pink hue. Quatrefages attributed a physiological value to these coloured bands, describing them as being connected with the respiratory function. In connection with the whole subject of cutaneous respiration in annelids, it appeared important to settle this question, and the author made sections of the anterior segments in the Maldanidæ, and finds the colour to be due to a special pigment, whose behaviour under various reagents he described. On the other hand the author has studied the blood-vessels and their distribution in the living chætopod, and is satisfied that it extends equally in those portions of the cuticle which are uncoloured as in those which are. The coloured bands do not appear, therefore, to be in any way connected with the function of respiration.

\section{SECTION E-GEOGRAPHY}

The Indian Forest School, by Major F. Bailey, F.R.G.S., Royal Engineers, Director of the School.-It is only within the last twenty-five years that a special State department has administered the Indian forests. The staff was at first composed of men who had received no professional education, but they were able to do all that was then needed, and they accomplished work of great value. But as a result of their work the State became possessed of large forest areas, from which a permanent supply of produce had to be sectred, and which had therefore to be managed systematically. At this time nothing was known of systematic forestry in England or in India, and an arrangement was made in 1866 under which candidates for the Indian Forest Service were trained on the Continent. The arrangement with the French Government is still in force, but it has now been decided to undertake the instruction in England. Great progress has been made in Indian forestry, which is mainly due to the professionally-trained men with whom the Forest Department has been recruited, but up to 1869 nothing bad been done towards the education of the subordinate ranks. As work requiring professional skill became necessary over large areas, it was found that the "divisions" must be broken up into a number of smaller executive charges under natives of the country, and that they must receive a professional education. In $1869 \mathrm{Mr}$. Brandis made proposals to organise the subordinate grades and to train men at the Civil Engineering Colleges, and several other attempts were made in the same direction, but without marked success. In $1878 \mathrm{Mr}$. Brandis proposed to establish a Central Forest School, and his proposals were accepted by Government. The chief object of the School was then to prepare natives of India for the executive charge of forest ranges, and to qualify them for promotion to the superior staff, but it was hoped that the school might ultimately be used to train candidates for the controlling branch. The chief forest officers of provinces were to select candidates and send them to be trained at the School. None but natives of India were to be admitted. A number of forests near Dehre Dun were grouped together as a training ground and placed under a separate conservator, who was also appointed director of the school. A board of inspection was appointed. The first theoretical course was held in 1881, and they have been held every year since then. The present system is that the candidates, who must be in robust health, are selected by conservators of the forest or by the director of the school. They must serve in the forests for at least twelve months before entering the School. Candidates for the ranger's certificate must have passed the entrance examination of an Indian University on the English side ; candidates for the forester's certificate pass a lower examination. The course of training for these two classes extends over eighteen and twelve months respectively. Men who gain the certificates return to their provinces, and are employed there. The course of instruction for the ranger's class embraces vegetable physiology, the elements of physics and chemistry, mathematics, road making and building, surveying, sylviculture, working plans, forest utilisation, forest botany, the elements of mineralogy and geology, forest law, and the elements of forest etiology. The course for foresters is much more simple. The preparation of manuals is in progress, and a library, museum, chemical laboratory, observatory, and forest garden have been established. The period of probation in the forest before entry into the School has a twofold object : firstly, to enable the theoretical course to be understood; secondly, to eliminate men who are unsuited to a forest life before time and money have been spent on their training. As a rule, the students are employés of the Forest Department, and they draw their salaries and maintain themselves while at the School. No instruction fees are charged. It would not at present be possible to get condidates whose maintenance and education are entirely paid for by their friends. Nine men who have left the School have appointments of from 125l. to $200 l$ a year, and this ought to draw eligible candidates. Conservators of forests say that the men trained at the School are markedly superior to their untrained comrades. The area of reserved forests has largely increased of late, and the prospects of the students are very good. During the session of 1884 there were forty-six students of all classes at the School, of whom eight were from Madras, and seven from native States, the chiefs of which have been induced by the establishment of the school to take measures for the protection of their forests. The School has now been made an imperial institution, and this is a great advantage in every way. The expenses of the School in 1884 are said to have been IgIIl.

On Fourneyings in South-Western China, by A. Hosie.-In the autumn of I881 Mr. Hosie was appointed Her Majesty's Agent in Western China, and reached Ch'ung-ch'ing, in the province of Ssur-ch'uan, in January, I882. From this point he made three journeys in South-Western China. In the spring of I 882 he proceeded through Southern Ssŭ-ch 'uan and Northern Kuei-chou, the Chinese "Switzerland," to Kuei-yang Fu, the capital of the latter province, whence he journeyed westward in the footsteps of Margary to the capital of Yuinnan. From Yünnan $F u$ he struck north-east through Northern Yünnan, following for days here and there the routes of Garnier and the Grosvenor Mission. At last he descended the Nan-kuang River and reached the right bank of the Great River, the local name of the Upper Zangtsze, at a point below Hsii-chou Fu, an important city at the junction of the Min River and the Chin-sha Chiang, or River of Golden Sand. Here he took boat and descended the Great River to $\mathrm{Ch}^{\text {' } u n g-c h}$ 'ing, his starting-point. In February, I883, Mr. Hosie again left $\mathrm{Ch}^{\text {' }} \mathrm{ung}$-ch'ing, and proceeded north-west to $\mathrm{Ch}$ 'êng-tu, the capital of the province of Ssur-ch'uan, by way of the brine and petroleum wells of Tzŭ-liu-ching. From Ch 'êng-tu he journeyed west and southwest through the country of the Lolos, skirting the western boundary of Independent Lolodom. From Ning-yiian, locally called Chien-ch'ang, and lying in a valley famous, among other things, as the habitat of the white-wax insect, he passed southwest through the mountainous Cain-du of Marco Polo, inhabited in great part by Mantzŭ tribes, and struck the left bank

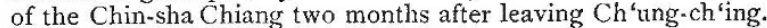
From this point Ta-li $\mathrm{Fu}$, in Western Yünnan, was easily reached. From Ta-li $\mathrm{F}_{\mathrm{u}} \mathrm{Mr}$. Hosie jurneyed eastward to $\mathrm{Y}$ ünnan $\mathrm{Fu}$, which he had visited the year before, and then struck north-east through Western Kuei-chou to the Yung-ning River, which he descended to the Great River. Lu Chou, an important city at the junction of this river with the $\mathrm{T}^{\circ} \mathrm{O}$ River, was soon reached, and the Great River was again descended to Ch'ung-ch'ing. This journey occupied four months. In June, 1884, Mr. Hosie again left Ch'ung-ch'ing, and from Ho Chou, a three days' journey to the north of that city, he struck westward through a beautifully cultivated and fertile country to Chiating $\mathrm{Fu}$, on the right bank of the Min at its junction with the $T^{\prime}$ ung River. Chia-ting is famous as the great centre of sericulture in Ssŭ-ch'uan, and as the chief insect wax-producing country in the Empire. A day's journey west of Chia-ting is the famous Mount O-mei, rising I I, 100 feet above the level of the sea. This mountain, which is sacred to the worship of Buddha, Mr. Hosie ascended in company with crowds of pilgrims. He then proceeded south, skirting the eastern boundary of Independent Lolodom, to the River of Golden Sand, the left bank of which was struck at the town of Man-i-ssŭ, between 